\title{
HUBUNGAN PEMAHAMAN ISI PESAN IKLANXL HOTROD 4G LTE PAKET TRULY UNLIMITED DENGAN MINAT BELI PRODUK KARTU XL
}

\author{
Achmad Bulkis \\ Mahasiswa Program Studi Magister Ilmu Komuniaksi FISIP UNDIP Angkatan IV \\ Email:
}

\begin{abstract}
ABSTRACK
The phenomenon of "cost war" between mobile phone operators which followed by a decrease in cost policy, would bring benefits to communications service users. This thing happens as the result of telecommunications world development that rapidly increase to inform and persuade the society.

The learning hierarchy theory explains that any information (including advertising of certain products) will give exposure to the consumers and consequently changes their cognitive component including awareness, attention and understanding of consumers towards the product which can led to the further changes

This type of this research is explanatory researchthat explain the relationship or correlation between the level of understanding the advertising messages (X1) and buying interest on XL card product (Y). The population of this research is village residents of Pleburan, Southern District of Semarang.

The results showed that higher levels of understanding advertising messages XL is is directly proportional to the higher level of buying interest on XL card, otherwise the lower level of understanding advertising messages XL is directly proportional to the lower buying interest on $X L$ card.
\end{abstract}

Keywords: The learning Hierarcy, cost wars, the internet, buying interest, understanding messages

\section{PENDAHULUAN}

Salah satu fenomena yang saat ini sedang terjadi di masyarakat adalah iklan biaya murah tarif akses internet melalui telepon seluler atau biasa disebut-sebut sebagai "perang" tarif. Hal tersebut terjadi seiring perkembangan dunia telekomunikasi yang kian pesat. Masing-masing operator telepon seluler berlomba memberikan fasilitas akses internet dengan biaya yang paling murah dan cepat. Fenomena tersebut mengisyaratkan adanya beberapa perubahan paradigma pada perilaku orang dalam melakukan komunikasi dimana saja, kapan saja, dan siapa saja. Saat ini semua orang mulai dari yang tinggal di desa maupun kota, memiliki perangkat ponsel yang sebelumnya merupakan sebuah keistimewaan bagi segelintir orang saja. Orang menyebutnya sebagai sebuah revolusi bergerak (mobilerevolution). Jasa komunikasi sepertinya sudah menjadi komoditas yang setara dengan komoditas pokok lainnya sehingga tidak mengherankan jika komunikasi menjadi lahan yang diperebutkan baik oleh BUMN seperti PT.TELKOM ataupun perusahaan operator telepon. 
Inti dari dari setiap iklan operator seluler adalah mereka secara tidak langsung ingin mengatakan kalau "operator kami yang paling menguntungkan Anda. Pakailah operator kami sekarang!". Program operator lain lebih jelek, atau tarif yang diberikan operator lain itu palsu, menjebak dan sebagainya. Mereka tidak mengungkapkan promosi mereka secara detail, tetapi hanya mengungkapkan sisi baiknya saja dan menyimpan sisi lainnya dan membungkusnya dengan tanda bintang $\left(^{*}\right)$ yang berarti syarat dan ketentuan berlaku.Seperti hasil riset yang telah disebutkan diatas, $80,47 \%$ pemirsa TV menyatakan menyukai iklan yang lucu dan $66 \%$ lebih menyukai iklan yang memberikan lebih banyak informasi mengenai produk yang diiklankan

\section{(http://www.swa.co.id/primer/pemasaran/} advertising/ details.php?cid=1\&id=2234).

Iklan memang dibuat untuk membujuk dan memberikan informasi. Iklan harus menarik khalayak, menyedot perhatian mereka, merangsang keinginan mereka dan memberikan perhatian yang lebih tajam mengenai produk atau jasa yang diiklankan. Untuk menghasilkan itu diperlukan wawasan, imajinasi, serta keterampilan kreatif yang besar. Kekuatan dan tingkat efektifitas iklan terletak pada pesan (Fabey, 1997: 83). Sebuah pesan iklan disebut efektif bila pesan tersebut mampu menggambarkan apa yang dikehendaki oleh komunikator secara tepat dan apa yang dituangkan dalam pesan iklan tersebut mampu dipersepsi sama oleh khalayak dengan apa yang dikehendaki komunikator. Melalui pesan yang efektif ini diharapkan pesan akan mampu memberikan dampak tertentu pada khalayak yang sesuai dengan yang dikehendaki oleh komunikator.

Iklan dibuat untuk memberikan informasi yang berharga bagi masyarakat, informasi yang ditayangkan diharapkan bisa dimengerti, karena iklan adalah salah satu seni mengkomunikasikan produk kepada khalayak dengan harapan agar dilihat, didengar atau diperhatikan untuk dimengerti, bukan untuk membuat pemirsa bingung dan tidak mengerti sama sekali apa maksud yang terkandung dalam suatu iklan. Dan iklan juga digunakan oleh para pengiklan untuk membujuk, mendidik dan juga memberikan hiburan. Isi pesan iklan yang dipadu dengan teknik-teknik khusus juga perlu dibuat untuk dapat menarik perhatian masyarakat sehingga pesan iklan tersebut dapat digambarkan oleh masyarakat sesuai dengan apa yang diharapkan oleh komunikator.

Pada fenomena "perang" tarif yang marak terjadi antar operator telepon seluler yang diikuti dengan penurunan tarif, tentu menguntungkan bagi pengguna layanan komunikasi. Dan merupakan hal yang sah, dimana pelanggan seluler bisa mendapatkan layanan dengan harga yang semakin murah dan tentunya layanan yang tetap berkualitas. Hanya sayangnya, penurunan tarif tidak diimbangi dengan komunikasi yang memadai, yang bisa menjelaskan tentang keunggulan program masing-masing operator. Yang ada, para operator malah sibuk beriklan dengan pesan yang intinya mengatakan program operator lain lebih jelek, tarif yang diberikan operator lain itu palsu, menjebak dan sebagainya. Realitas ini yang menjadi perhatian, karena iklan-iklan tarif telekomunikasi tersebut dinilai menyesatkan karena tidak informatif.

Penelitian yang dilakukan R Wijayanti tahun 2008 menunjukkan bahwa ada pengaruh antara penayangan iklan Telkom Flexi di televise dengan minat belikon sumen sebesar $32,49 \%$ dan menggunakan koefisien korelasi. Penelitian lain yang dilakukan Aprilyana Saputri pada mahasiswa Fakultas Ekonomi UPN Jakarta tahun 2009 menunjukkan bahwa 
terdapat pengaruh sebesar 59,8\% iklan media televise terhadap keputusan pembelian konsumen provider Simpati dengan teknik purposive sampling.

Sebuah pesan iklan disebut efektif bila pesan tersebut mampu dipahami sesuai dengan apa yang dikehendaki oleh komunikor secara tepat dan apa yang dituangkan dalam pesan iklan tersebut juga mampu dipersepsi sama oleh khalayak dengan apa yang dikehendaki komunikator. Melalui pesan yang efektif ini diharapkan pesan akan mampu memberikan dampak tertentu pada khalayak yang sesuai dengan yang dikehendaki oleh komunikator salah satunya yaitu adanya perubahan minat beli (interest) setelah tahap sebelumnya adalah perhatian (Attention).

Thelearninghierarcy (teori hirarki belajar) ini menerangkan bahwa setiap informasi (termasuk iklan tentang produk tertentu) akan menerpa konsumen dan akibatnya terjadi perubahan komponen kognitif dari konsumen itu. Perubahan itu meliputi kesadaran, perhatian, pemahaman konsumen terhadap produk yang diiklankan. Kalau itu sudah sukses baru mengakibatkan perubahan lanjutan. Konsumen lalu menunjukkan perilaku yang nyata terhadap produk yang diinformasikan melalui iklan dengan mencoba mengadopsikannya.

Melalui pesan yang efektif diharapkan pesan mampu memberikan dampak pada khalayak yaitu adanya perubahan minat beli (interest). Dari uraian tersebut dapat ditari khipotesis bahwa pemahaman terhadap isi pesan iklan memiliki hubungan dengan minat beli.

Disini peneliti akan mengkhususkan penelitian pada usia 15 - 44 tahun. Berdasarkan penjelasan diatas maka penelitian ini akan membahas, apakah tingkat pemahaman isi pesan dari tayangan iklan XL versi xl hotrod 4G LTE pakettruly unlimited dapat menarik minat beli masyarakat terhadap produk kartu perdana XL. Penelitian ini bertujuan untuk mengetahui hubungan tingkat pemahaman isi pesan dari tayangan iklan dengan minat membeli produk kartu perdana XL.

\section{METODE}

Tipe penelitian yang digunakan adalah explanatoryresearch yang menjelaskan tentang hubungan atau korelasi antara tingkat pemahaman isi pesan iklan (X1) dengan minat beli produk kartu perdana XL (Y). Populasi yang diambil adalah warga Kelurahan Pleburan Kecamatan Semarang Selatan. Pemilihan populasi ini disebabkan adanya mayoritas dari penduduk Kelurahan Pleburan memiliki pekerjaan sebagai pengusaha, pedagang dan PNS yang tentunya memiliki kebutuhan akan komunikasi menggunakan telepon seluler yang tinggi, selain itu faktor kedekatan letak geografis antara peneliti dengan responden untuk efisiensi biaya dan waktu dalam penelitian. Dalam penelitian ini, populasi sasarannya adalah warga di lingkungan Kelurahan Pleburan, Kecamatan Semarang Selatan dengan usia antara 15-44 tahun yang pernah menyaksikan tayangan iklan tarif murah XL hotrod 4G LTE pakettruly unlimited dan belum menggunakan kartu XL. Teknik pengambilan sampel yang digunakan dalam penelitian ini adalah Proposional Random Sampling. Analisis data kuantitatif dilakukan berdasarkan pada tabulasi silang. metode statistik yang berguna menguji kebenaran hipotesis penelitian yakni menghitung atau membuktikan adanya korelasi tingkat pemahaman isi pesan iklan sebagai variabel bebas (independentvariable) dengan minat beli produk kartu perdana XL sebagai variabel terikat (dependentvariable). 


\section{HASIL PENELITIAN}

Tabel 1 Korelasi pemahaman isi pesaniklan xl hotrod 4G LTE pakettruly unlimited dengan minat beli produk kartu xl $(\mathrm{N}=94)$

\begin{tabular}{|c|c|c|c|c|c|}
\hline \multirow{2}{*}{$\begin{array}{l}\text { PemahamanTerhadap } \\
\text { Isi PesanIklan(X) }\end{array}$} & \multicolumn{5}{|c|}{ MinatBeli (Y) } \\
\hline & TidakBerminat & KurangBerminat & Berminat & SangatBerminat & Total \\
\hline TidakPaham & $(44 \%)$ & $\begin{array}{l}2 \\
(13 \%)\end{array}$ & $\begin{array}{l}6 \\
(37.5 \%)\end{array}$ & $\begin{array}{ll} & \\
& \\
& (6.25 \%)\end{array}$ & $\begin{array}{l}16 \\
(100 \%)\end{array}$ \\
\hline KurangPaham & 12 & $\begin{array}{ll}13 & \\
& \\
& (37 \%)\end{array}$ & $\begin{array}{l}9 \\
(25.71 \%)\end{array}$ & $\begin{array}{ll} & \\
& (2.86 \%)\end{array}$ & $\begin{array}{l}35 \\
(100 \%)\end{array}$ \\
\hline Paham & $\begin{array}{l}2 \\
(7 \%)\end{array}$ & $\begin{array}{ll} & \\
& (36 \%)\end{array}$ & 13 & (11\%) & $\begin{array}{l}28 \\
(100 \%)\end{array}$ \\
\hline SangatPaham & $\begin{array}{ll} & \\
& (6.67 \%)\end{array}$ & $\begin{array}{l}2 \\
\quad(13.33 \%)\end{array}$ & $\begin{array}{ll} & \\
& (60 \%)\end{array}$ & (20\%) & $\begin{array}{l}15 \\
(100 \%)\end{array}$ \\
\hline
\end{tabular}

Melalui tabel silang III.11 di atas dapat diketahui responden yang tidak paham terhadap isi pesan iklan maka responden tidak berminat untuk membeli produk Kartu Perdana XL, responden yang kurang paham terhadap isi pesan iklan juga kurang berminat untuk membeli produk Kartu Perdana XL sedangkan responden yang merasa paham dan sangat paham pada isi pesan iklan versi hotrod 4G LTE pakettruly unlimited memiliki minat untuk membeli kartu XL. Maka terdapat kecenderungan berhubungan antara variabel tingkat pemahaman isi pesan iklan versi hotrod 4G LTE pakettruly unlimited dengan variabel minat membeli kartu perdana xl bebas ekstra.

Adanya kecenderungan berhubungan antara variabel tingkat pemahaman isi pesan iklan XL hotrod 4G LTE pakettruly unlimited dengan minat membeli kartu perdana XL yang digambarkan pada tabulasi silang maka hipotesis penelitian dinyatakan terbukti, hal ini berarti terdapat hubungan positif antara variabel $\mathrm{X}$ dengan variabel $\mathrm{Y}$. Hal tersebut dapat dilihat pada tabel III.11, titik-tik pertemuan antara variabel $\mathrm{X}$ dengan variabel $\mathrm{Y}$, yang ditunjukkan dengan nilai tertinggi $44 \%$, 37\%, 46\%, dan 60\%, meskipun titik $60 \%$ tidak terletak pada garis diagonal dari kiri atas ke kanan bawah.

Angka-angka tertinggi tersebut menunjukkan bahwa semakin tinggi tingkat pemahaman isi pesan iklan kartu XL hotrod 4G LTE pakettrulyunlimited, maka semakin positif respon audience terhadap produk yang ditawarkan. Terlihat dari sebagian besar responden yaitu $60 \%$ yang menyatakan sangat paham pada isi pesan iklan kartu XL hotrod 4G LTE pakettrulyunlimited, memiliki respon yang positif terhadap produk yang ditawarkan yaitu Kartu Perdana XL.

Dan ada titik dimana responden menyatakan paham terhadap isi pesan iklan kartu XL hotrod 4G LTE paket trulyunlimited, mayoritas responden juga memiliki respon yang positif (keinginan untuk membeli produk 
juga tinggi). Tapi ada juga responden yang memiliki respon negatif terhadap produk yang ditawarkan (tidak ingin membeli produk yang ditawarkan). Terlihat dari responden yang kurang paham juga merasa kurang berminat terhadap produk yang ditawarkan (37\%) begitu juga dengan ketidakpahaman terhadap isi pesan iklan membuat responden tidak memiliki keinginan untuk membeli produk yang ditawarkan.

Hasil penelitian ini menunjukkan bahwa memang terbukti dengan semakin tinggi pemahaman isi pesan iklan, maka responden semakin berminat untuk membeli produk kartu perdana XL.

\section{PEMBAHASAN}

Periklanan adalah suatu komunikasi massa dan harus dibayar untuk menarik kesadaran, menanamkan informasi, mengembangkan sikap, atau mengharapkan adanya suatu tindakan yang menguntungkan bagi pengiklan (Kasali, 1995: 51). Setiap media dan sarana periklanan memiliki sifat/karakteristik dan kelebihan yang unik. Para pengiklan berusaha untuk memilih media dan sarana yang karakteristiknya paling cocok dengan merek yang diiklankan untuk mencapai khalayak sasarannya dan menyampaikan pesan yang dimaksud. Bila tujuannya untuk menyampaikan manfaat produk, televisi merupakan media yang terbaik(Shimp, 2003: 506).

Iklan didesain untuk mencapai beberapa tujuan :

1. membuat pasar sasaran menyadari (aware) akan suatu merek baru.

2. memfasilitasi pemahaman konsumen tentang berbagai atribut dan manfaat merek yang diiklankan dibandingkan merek-merek pesaing.

3. meningkatkan sikap-sikap dan mempengaruhi niatan untuk membeli.
4. menarik sasaran agar mencoba produk.

5. mendorong perilaku pembelian ulang (Shimp,2003: 368).

Inti dari kegiatan periklanan adalah menemukan ide yang relevan untuk komunikan sehubungan dengan isi dan kegunaan pesan sehingga ia tergerakkan untuk bertindak. Pesan yang disebarkan dalam periklanan haruslah untuk pihak komunikan merupakan:

1. Pemberian informasi yang baru ataupun pelengkap terhadap informasi yang dimilikinya mengenai hal yang berhubungan dengan apa yang disebut dengan pesan.

2. Informasi yang baru dapat membantu komunikan untuk mengadakan organisasi dan reorganisasi dari pemikiran dan data yang telah dimilikinya, sedemikian rupa sehingga pilihannya jatuh pada informasi terakhir.

3. Isi harus mempunyai nilai kepentingan (=significance) untuk komunikan, yaitu setelah ia membentuk dan mengadakan organisasi dan reorganisasi data yang dimiliki dan ditambah dengan data terakhir (Susanto, 1977: 209-210).

Memahami adalah mengerti dan dapat menciptakan arti dari stimulus dan simbolsimbol yang ada. Komunikasi menjadi efektif ketika arti yang ingin disampaikan oleh komunikator pemasaran sesuai dengan apa yang benar-benar ditangkap oleh konsumen dari pesannya. Istilah Pemahaman (comprehension) sering digunakan bergantian dengan persepsi (Perceptions); kedua istilah tersebut disebut juga interpretasi (Shimp, 2003: 189-190).

\section{Pemahaman}

(comprehension) mengacu pada proses interpretasi yang melaluinya konsumen memahami atau merasakan perilaku mereka dan aspek relevan 
lingkungan mereka. Pada saat memahami, konsumen membangun arti dan membentuk struktur pengetahuan yang mewakili konsep, obyek, perilaku, dan kejadian yang menonjol.

Minat konsumen potensial atas produk yang ditawarkan di pasar, pada dasarnya terbagi atas tiga tahapan, yaitu mengetahui, terpengaruh, dan bertindak untuk melakukan pembelian. Model-model yang pada umumnya dipakai untuk melihat tahapantahapan ini pada umumnya adalah model AIDCA, AIDA, Hierarchy of effects, dan adoptasi inovasi.

Dari ke empat model diatas, salah satu yaitu model AIDCA akan dipaparkan seperti berikut :

\section{Attention (perhatian)}

Pada tahap ini iklan yang ditayangkan harus dapat menarik perhatian khalayak sasarannya. Jika tahapan ini berhasil, maka tahap selanjutnya menjadi tidak berguna. Dengan mengetahui hasil pada tahap ini perusahaan sudah dapat mengevaluasi program periklanan yang dilaksanakan.

2. Interest (Minat)

Jika perhatian khalayak sasaran berhasil direbut iklan yang ditayangkan hendaknya dapat membuat pemirsa berminat untuk mengetahui lebih lanjut mengenai produk yang diiklankan. Untuk itu pemirsa harus dirangsang agar mau mengikuti pesanpesan iklan tersebut.

3. Desire (Hasrat)

Iklan dapat menggerakan keinginan pemirsa untuk memiliki atau menikmati produk tersebut. Kebutuhan atau keinginan mereka untuk memiliki, memakai, atau melalukan sesuatu sebagai kelanjutan tahap interest.

\section{Conviction (Rasa Percaya)}

Sampai tahap ini tujuan perusahaan melalui iklan telah berhasil menciptakan kebutuhan calon pembeli, sudah mulai goyah dan emosinya mulai tersentuh, tetapi masih timbul keraguan. Dalam kondisi ini hendaknya iklan harus dapat meyakinkan atau menimbulkan rasa percaya diri.

5. Action (Kegiatan)

Pada tahap ini hendaknya calon pembeli sudah dapat mengambil keputusan membeli atau tidak, tetapi belum sungguhsungguh berusaha untuk membeli, mungkin keinginan untuk membeli sudah diputuskan tetapi pembelian belum juga dilaksanakan karena ada kendala. Untuk itu iklan harus dapat menuntun calon pembeli untuk mengambil langkah akhir berupa tindakan pembelian (Umar, 2002: 246-247).

\section{PENUTUP}

Isi pesan iklan dibagi dua, yaitu komponen verbal (lisan) dan visual (tulisan). Baik komponen verbal maupun visual mungkin mempengaruhi pembentukan kepercayaan konsumen terhadap atribut produk serta perasaan dan emosi konsumen. Perasaan dan emosi yang diekspresikan konsumen ketika melihat iklan mempengaruhi sikap konsumen terhadap iklan, yang nantinya akan mempengaruhi sikap konsumen terhadap merek. Kepercayaan konsumen terhadap atribut produk mungkin juga mempengaruhi sikap konsumen terhadap merek. (Simamora, 2002: 175)

Hasil kuesioner yang disebarkan menyatakan bahwa responden kurang paham terhadap isi pesan iklan kartu XL hotrod $4 \mathrm{G}$ LTE paket trulyunlimited, hal tersebut dapat dilihat dari kurangnya kemampuan responden dalam mengingat simbol-simbol atau hal-hal yang berkaitan dengan iklan kartu XL dan juga mengingat isi pesan iklan, hanya sekitar $15.96 \%$ responden yang sangat paham pada isi pesan iklan. Walaupun responden kurang paham terhadap isipesaniklankartu XL hotrod 4G LTE pakettrulyunlimited, responden tetap 
berminat untuk membeli kartu perdana XL yaitu sejumlah $39.36 \%$.

Dari tabulasi silang (Cross Tab) dapat dilihat keteraturan pola pada tabulasi silang apabila ditarik garis persentase tertinggi tiaptiap persilangan kategori dari variable hubungan pemahaman isi pesan iklan kartu XL hotrod 4G LTE paket truly unlimited (X) dengan minat membeli kartu perdana XL (Y) menunjukan bahwa antara variabel $\mathrm{X}$ dan $\mathrm{Y}$ terdapat kecenderungan berhubungan, sehingga hipotesis yang berbunyi terdapat hubungan pemahaman isi pesan iklan kartu XL hotrod 4G LTE paket trulyunlimited dengan minat membeli kartu perdana XL terbukti. Jadi semakin tinggi tingkat pemahaman isi pesan iklan XL maka semakin tinggi tingkat minat beli kartu perdana XL, dan sebaliknya semakin rendah tingkat pemahaman isi pesan iklan XL maka semakin rendah tingkat minat beli kartu perdana XL.

Supaya lebih diminati oleh responden, PT. Excelcomindo juga perlu membuat iklan yang lebih menarik, jika perlu menggunakan unsure komedi, karena dilihat dari hasils urvei ini, responden banyak yang mengingatiklan XL versi menikah dengan kambing dan menikah dengan monyet, dimana kedua iklan tersebut menggunakan unsure komedi didalammnya.

\section{DAFTARPUSTAKA}

\section{Buku}

Fabey, A D. (1997). How to Produce Succesful Advertisin. Jakarta: PT Gramedia Pustaka. Utama

Kasali, Rhenald. (1995). Manajemen Periklanan - Konsep dan Aplikasinya di Indonesia, Jakarta : Pustaka Utama Grafiti.

Shimp, Terence. (2003). Periklanan dan Promosi. Jakarta: Erlangga

Simamora, Bilson. (2002). Panduan Riset Perilaku Konsumen. Jakarta: PT. Gramedia Pustaka Utama

Susanto, Astrid S. (1977). Komunikasi Dalam Teoridan Praktek, Bandung: Bina Cipta

Umar, Husein. (2002). Evaluasi Kinerja Perusahaan. Jakarta: PT Gramedia Pustaka Utama

\section{Skripsi}

Prakoso, W. G. (2014). Analisis Sikap Pemirsa Terhadap Iklan Internet Service Provider Smartfren Di Televisi. Jurnal Manajemen Bisnis, volume 3 nomor 1 .

Wijayanti, R. (2008). Pengaruh Penayangan Iklan Telkom Flexi Di Televisi Terhadap Minat Beli Konsumen (Doctoral dissertation, Universitas Widyatama).

\section{Internet}

http://www.swa.co.id/primer/pemasaran/ advertising/ details.php?cid $=1 \& \mathrm{id}=2234$ 